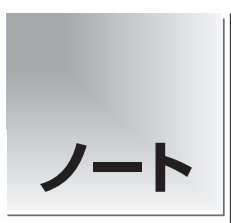

論文受付 2012 年 6 月 15 日

論文受理 2012 年 8 月 29 日 Code Nos. 400 430

\section{Image Guided Radiation Therapy における 6 軸位置補正法の検討}

\author{
中口裕二 ${ }^{1,2}$ 荒木不次男 ${ }^{3}$ 河野友宏 $^{2}$ 丸山雅人 ${ }^{1}$ \\ 1 熊本大学医学部附属病院医療技術部 \\ 2 熊本大学大学院保健学教育部 \\ 3 熊本大学大学院生命科学研究部
}

\section{緒 言}

定位放射線治療 (stereotactic radiation therapy: SRT) や定位放射線手術 (stereotactic radiation surgery: SRS) などの高精度放射線治療では, 通常の放射線治療に比 べ gross tumor volume (GTV)に対する margin が少な く，より正確なセットアップが不可欠である1,2). 正確な セットアップのため治療直前に位置確認画像を取得 し，基準画像との照合によって，位置変位量を算出・補 正する画像誘導放射線治療 (image guided radiation therapy: IGRT)が用いられ，多くの施設で実施可能と なっている.さらに, 頭尾, 腹背, 左右の 3 軸にそれぞ れの回転を加えた 6 軸カウチが開発され，6 軸方向の正 確な位置補正が実現されている3 。 今後, 高精度放射
線治療の普及とともに6 軸補正の使用頻度がさらに拡 大すると考えられる。

現在, 6 軸補正が可能な IGRT システムには, 医療用 直線加速器(リニアック)に装備された $\mathrm{kV}$-X-ray Volume Imaging (kV-XVI: Elekta 社製) や kV-On-Board Imager (kV-OBI: Varian 社製)を用いたシステムなどがある。ま た,リニアックと独立して装備された ExacTrac X-ray システム (BrainLAB 社製)があり, 各リニアック装置と 組み合わせて使用されている。各 IGRTシステムの有 用性と精度はいくつか報告されている4,5)。

6 軸における物体の移動では，6 軸の座標変数による 座標変換が用いられている。回転がない場合は，任意 の順番で座標変換することによって, 移動が可能であ

\title{
A Practical Method for Six-dimensional Online Correction System with Image Guided Radiation Therapy
}

\author{
Yuji Nakaguchi, ${ }^{1,2 *}$ Fujio Araki, ${ }^{3}$ Tomohiro Kouno, ${ }^{2}$ and Masato Maruyama ${ }^{1}$ \\ ${ }^{1}$ Department of Radiological Technology, Kumamoto University Hospital \\ ${ }^{2}$ Graduate School of Health Sciences, Kumamoto University \\ ${ }^{3}$ Faculty of Life Sciences, Kumamoto University
}

Received June 15, 2012; Revision accepted August 29, 2012

Code Nos. 400,430

\section{Summary}

In this study, we developed a correction method for coordinate transformation errors that are produced in combination with the ExacTrac X-ray system (BrainLAB) and HexaPOD (Elekta) in image guided radiation therapy (IGRT). The positional accuracy of the correction method was compared between the ExacTrac Robotics (BrainLAB) and no correction. We tried to correct iBeam evo couch top (Elekta) by operating two steps drive like ExacTrac Robotics. No correction for HexaPOD showed a maximal error of $4.52 \mathrm{~mm}$, and the couch did not move to the correct position. However, our correction method for HexaPOD showed the positional accuracy within $1 \mathrm{~mm}$. Our method has no significant difference with ExacTrac Robotics (paired t-test, $\mathrm{P}>0.1)$. But, when the correction values for the rotatory directions were large, the positional accuracy tended to be poor. The smallest setup errors for the rotatory directions are important for IGRT.

Key words: accuracy, six degrees, 6D couch, image guide radiotherapy, couch drive

*Proceeding author 
る.しかし, 回転が含まれる場合では, 移動する順番 が重要で, 順番次第では異なる位置に移動する. IGRT システムの 6 軸カウチの移動に関しても同様に, 行列に よる座標変換が用いられ ${ }^{6}$ ，座標の移動順番によって移 動座標が変化する可能性がある. BrainLAB 社製 6 軸 カウチでは, 最初に回転方向の座標移動が行われ, 次 に3 軸 $(\mathrm{x}, \mathrm{y}, \mathrm{z})$ の平行移動が行われる，2段階移動方 式である。これに対して，Elekta 社製 6 軸カウチは， 6 軸が同時に移動して座標の位置移動が行われる。 ExacTrac X-ray システムと Elekta 社製 6 軸カウチを組 み合わせて使用する場合は, Elekta 社製 6 軸カウチと BrainLAB 社製 6 軸カウチの移動方式が異なるために, ExacTrac X-ray システムで計算する 6 軸の移動座標に 補正が必要となる。したがって, Elekta 社製 6 軸カウチ に ExacTrac X-ray システムの 6 軸の移動座標を補正な しで用いると，カウチが正しい位置に移動せず，誤った 位置で治療を行い，医療事故に繋がる可能性がある。 これまで, ExacTrac X-ray システムと Elekta 社製 6 軸 カウチ，および，その制御システムである HexaPOD と の組み合わせで使用する際の位置座標の補正に関する 報告はなく，また，これらのシステムを組み合わせた位 置補正精度に関する報告もない，臨床使用に招いて は，位置精度の検証を行う必要がある。

本研究では，ExacTrac X-ray システムと Elekta 社製 6 軸カウチを組み合わせた IGRT の位置補正法を考案 し, その位置精度の改善について位置補正を行わない 場合と, さらにBrainLAB 社製 6 軸カウチによる位置精 度とを比較・検討した。

\section{1. 使用機器}

6 軸カウチは, ExacTrac Robotics(BrainLAB 社製) と iBeam evo couch top(Elekta 社製)を用い，両 6 軸カウ チの補正座標の計算に ExacTrac X-ray システム version 5.5.2を用いた. iBeam evo couch top の制御システムは HexaPOD version 1.1 (Elekta 社製)である. 位置精度検 証ファントムは, 腰部ファントム PUB-3 (京都科学社製) を使用した。治療計画装置は, Pinnacle version 9.0 (Philips 社製)で, computed tomography は Light Speed RT (GE 社製)を使用し，スライス厚は $2.5 \mathrm{~mm}$ で撮影した。

\section{2. 方 法}

最初に, ExacTrac X-ray システムと iBeam evo couch top を組み合わせて, HexaPODの座標計算に2-1の項 の位置補正を行わない場合 $[\mathrm{HexaPOD}$ (補正なし) $]$ と, 位置補正を行う場合 $[\mathrm{HexaPOD}$ (補正あり)]で位置精度 を比較した。次に, HexaPOD(補正あり)と ExacTrac
X-ray システムとExacTrac Roboticsの組み合わせ (ExacTrac Robotics)との位置精度を比較した。

\section{2-1 HexaPOD 用の位置補正法の考案}

本研究では, ExacTrac X-ray システムと HexaPOD を 組み合わせたIGRTに打ける位置座標の補正法とし て, 最初に回転方向を補正し, 次に 3 軸の水平移動を 行い, iBeam evo couch top E ExacTrac Robotics と同様 の 2 段階で操作することによって補正を行った。また, 単位が $\mathrm{mm}$ と $\mathrm{cm}$ で異なり, さらに角度表記も異なるた め，単位を表計算ソフト Excel(マイクロソフト社製)の マクロ機能を使用して計算した. ExacTrac X-ray システ ムでは，小数点以下第二位まで補正可能であるが, HexaPOD では小数点以下第一位までしか入力できな い箇所があるため, 必要に応じて, ExacTrac X-ray システムの最小桁は四捨五入を行った。実際には,

ExacTrac X-ray システムから与えられる回転方向の值 のみを使用し, Excel を用いて単位を変換し, 最初に回 転方向のみの補正を行った。次に, ExacTrac X-ray シ ステムの赤外線カメラによる計測から得られる 3 軸平行 移動の座標を Excelに入力し, 単位変換後, 3 軸の平 行移動を行った，位置座標補正のワークフローと座標 系をそれぞれ Fig. 1 と Fig. 2 に示す。

\section{2-2 セットアップ}

ExacTrac X-ray システムは赤外線マーカによるセット アップが可能であるが，当院では他の IGRT システムで も治療を行うため, 皮虐マーカによるセットアップを 行っている，皮膚マーカによるセットアップを行ったと しても, カウチの移動には赤外線マーカが必要である. したがって, カウチ移動のための赤外線マーカにはリ ファレンススター(BrainLAB 社製)を用いた。一方，

HexaPOD では ExacTrac X-ray システムと HexaPOD 用 の赤外線マーカ, リファレンススターのほかに, リファ レンスフレーム(Elekta 社製)を用いた。これは，ExacTracX-ray システムはリファレンススターのみで位置検 出から補正まで可能であるが, HexaPODではリファレ ンススターで位置検出を行い, リファレンスフレームで カウチの移動・補正を行うためである. Fig. 3 に両シス テムのファントムのセットアップを示す。

\section{2-3 位置補正精度の比較}

腰部ファントム PUB-3 を使用し，両システムにおい て，6 軸の位置をアイソセンタから毎回任意にずらした 後にIGRTを行った. IGRT 後のアイソセンタからの位 置誤差を計測した，誤差の計測には，再度 IGRTを行 


\section{First step : rotation correction}

\begin{tabular}{|c|c|c|}
\hline \multicolumn{3}{|l|}{ Shift } \\
\hline Ventical & 1.30 & -0.34 \\
\hline Longiteral & 7.50 & 0.01 \\
\hline Lateral & 0.83 & 1.24 \\
\hline
\end{tabular}

ExacTrac X-ray system

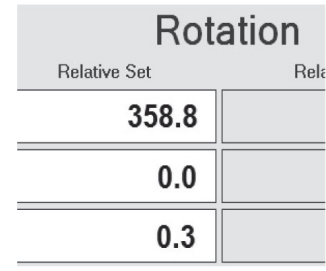

HexaPOD

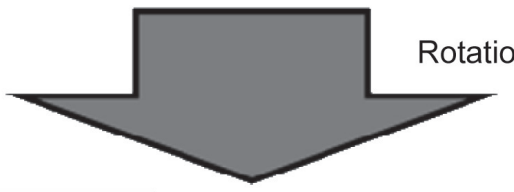

Second step : translation correction

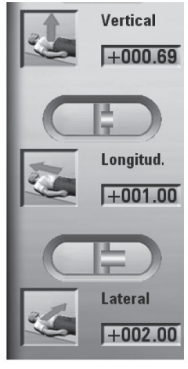

ExacTrac X-ray system

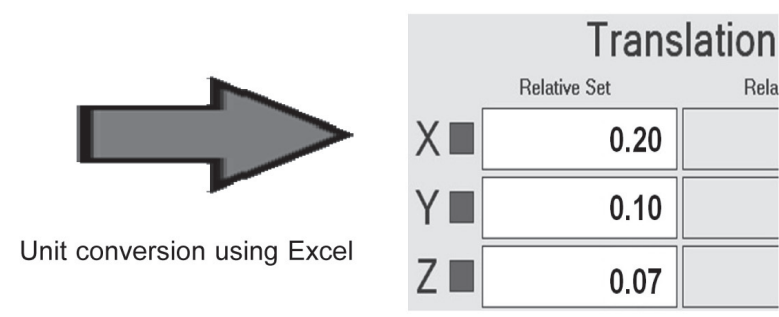

HexaPOD

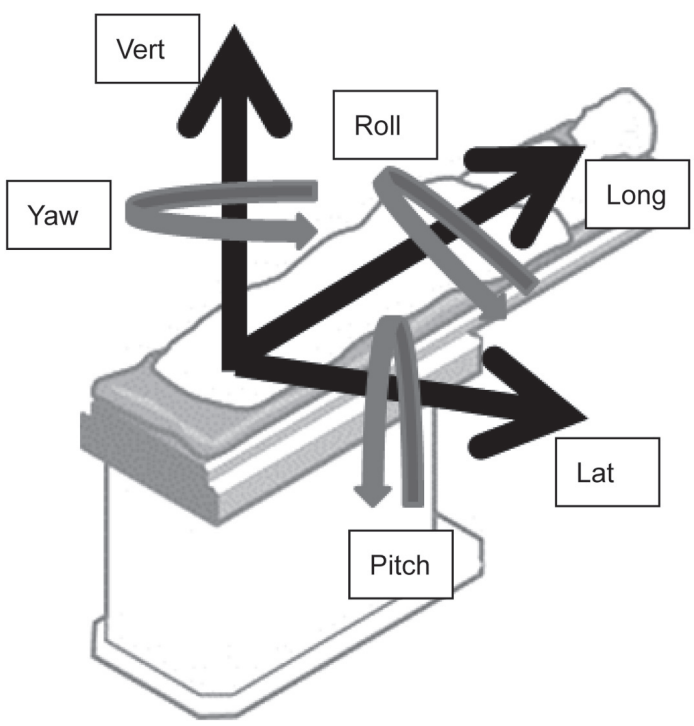

Fig. 2 The coordinate system. Long: cranio-caudal direction.

Lat: right-left direction, Vert: anterior-posterior direction, Roll: right roll-left roll direction, Pitch: head up-head down direction, Yaw: counterclockwise-clockwise direction.

The 6D correction was performed with two steps (rotation correction and translation correction).
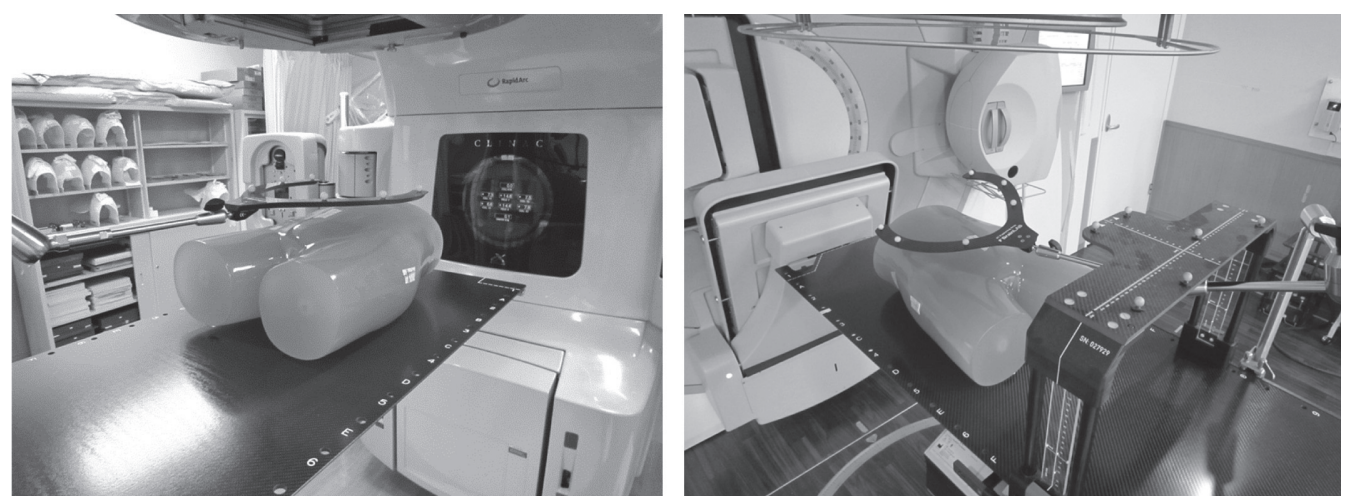

$\mathrm{a} \mid \mathrm{b}$

Fig. 3 Positioning of phantom using (a) ExacTrac X-ray system and Reference Star frame for Clinac iX, and (b) ExacTrac X-ray system, HexaPOD, and Reference Star frame for Synergy. 

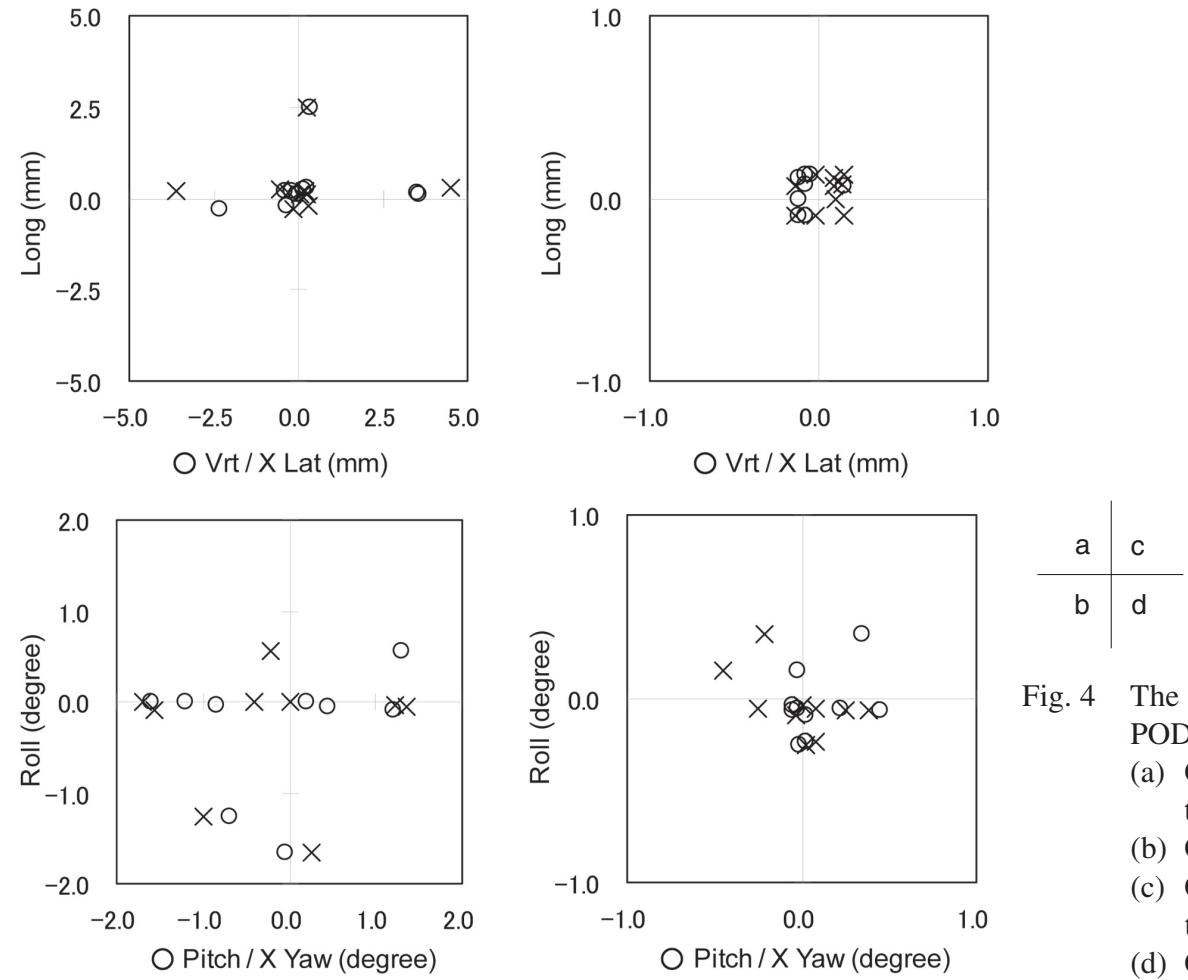

Fig. 4 The accuracy of the 6D correction for the HexaPOD.

(a) Correction (-); long, vertical and lateral translation.

(b) Correction (-); roll, pitch, and yaw rotations.

(c) Correction (+); long, vertical and lateral translation.

(d) Correction (+); roll, pitch, and yaw rotations.

Table 1 The accuracy of the 6D correction for HexaPOD

(a) correction (-)

\begin{tabular}{lcccccccc}
\hline \hline & \multicolumn{3}{c}{ Translation $(\mathrm{mm})$} & & & \multicolumn{3}{c}{ Rotation (degree) } \\
\cline { 2 - 4 } \cline { 7 - 9 } & Ave & SD & Max & & & Ave & SD & Max \\
\hline Vert & 1.11 & 1.79 & 3.55 & Yaw & 0.88 & 1.11 & 1.35 \\
Long & 0.43 & 0.78 & 2.50 & Pitch & 0.79 & 0.98 & 1.30 \\
Lat & 1.01 & 1.94 & 4.50 & Roll & & 0.60 & 0.93 & 0.56 \\
3D & 2.18 & 1.62 & 4.52 & & & & & \\
\hline
\end{tabular}

(b) correction $(+)$

\begin{tabular}{lcccccccc}
\hline \hline & \multicolumn{3}{c}{ Translation $(\mathrm{mm})$} & & & \multicolumn{3}{c}{ Rotation (degree) } \\
\cline { 2 - 4 } \cline { 7 - 9 } & Ave & SD & Max & & & Ave & SD & Max \\
\hline Vert & 0.11 & 0.11 & 0.15 & Yaw & 0.18 & 0.18 & 0.38 \\
Long & 0.09 & 0.09 & 0.13 & Pitch & 0.12 & 0.17 & 0.45 \\
Lat & 0.10 & 0.11 & 0.15 & Roll & & 0.13 & 0.24 & 0.35 \\
3D & 0.18 & 0.03 & 0.22 & & & & & \\
\hline
\end{tabular}

Ave: average absolute error; SD: standard deviation; Max: maximum absolute error

い, ExacTrac X-ray システムの赤外線カメラから得られ る值を用いた。赤外線カメラは, アイソセンタに対し $\pm 0.05 \mathrm{~mm}$ 以内の精度で校正されている。 ファントムを ずらす位置は，当院における皮膚マーカでのセットアッ プの精度を考慮して $5 \mathrm{~mm}$ とした. 3 軸方向にそれぞれ $5 \mathrm{~mm}$ ずらし, 回転はそれぞれの回転軸に沿って 0.5, 1.0，3.0 度をずらした. 3 軸の平行移動方向と回転方向 は任意の組み合わせで行った。それぞれの測定は 10 回 行った.

\section{3. 結 果}

HexaPOD の位置補正精度の結果を Fig. 4 と Table 1 に示す。補正なしでは, 三次元での最大位置誤差 $4.52 \mathrm{~mm}$, 平均で $2.18 \pm 1.62 \mathrm{~mm}$ (1 standard deviation: SD)であり, 回転方向で 1.35 度の最大誤差となった。 補正ありでは三次元での最大位置誤差は $0.22 \mathrm{~mm}$, 平 均で $0.18 \pm 0.03 \mathrm{~mm}(1 \mathrm{SD})$ であり, 回転方向に関して は，最大位置誤差 0.45 度であった。一方, ExacTrac 


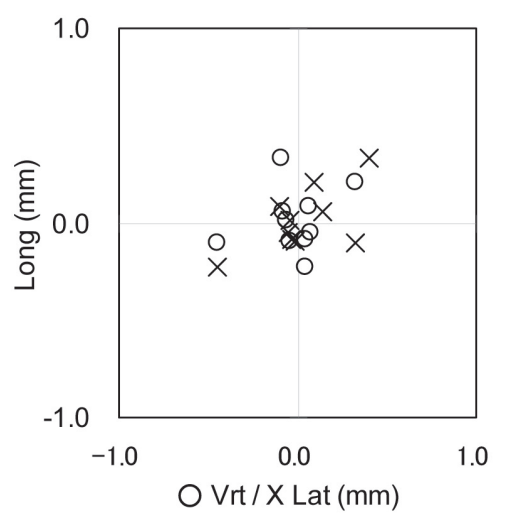

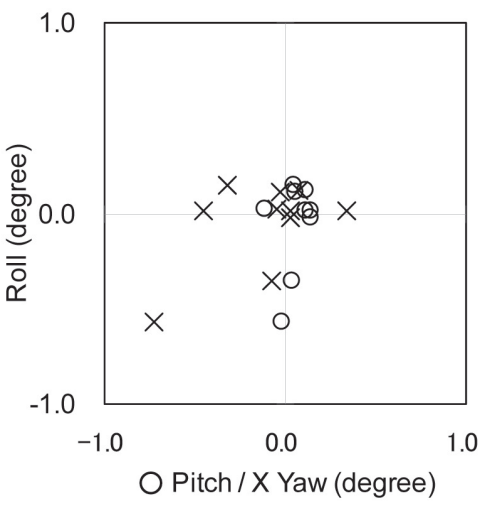

$a \mid b$

Fig. 5 The accuracy of the 6D correction for the ExacTrac Robotics.

(a) Long, vertical and lateral translation.

(b) Roll, pitch, and yaw rotations.

Table 2 The accuracy of the 6D correction for the ExacTrac Robotics

\begin{tabular}{|c|c|c|c|c|c|c|c|}
\hline & \multicolumn{3}{|c|}{ Translation (mm) } & & \multicolumn{3}{|c|}{ Rotation (degree) } \\
\hline & Ave & SD & $\operatorname{Max}$ & & Ave & SD & $\operatorname{Max}$ \\
\hline Vert & 0.13 & 0.19 & 0.32 & Yaw & 0.21 & 0.30 & 0.34 \\
\hline Long & 0.12 & 0.16 & 0.33 & Pitch & 0.09 & 0.08 & 0.14 \\
\hline Lat & 0.16 & 0.24 & 0.40 & Roll & 0.14 & 0.23 & 0.15 \\
\hline $3 \mathrm{D}$ & 0.27 & 0.20 & 0.56 & & & & \\
\hline
\end{tabular}

Ave: average absolute error; SD: standard deviation; Max: maximum absolute error

Robotics での位置補正精度の結果を Fig. 5 と Table 2 に 示す. 三次元での最大位置誤差は $0.56 \mathrm{~mm}$, 平均で $0.27 \pm 0.20 \mathrm{~mm}(1 \mathrm{SD})$ であり, 回転方向に関しては, 最 大位置誤差 0.34 度であった. ExacTrac Robotics と HexaPOD（補正あり）の位置精度の paired t-testによる有 意差検定では, 3 軸各方向, 三次元距離, 回転方向の いずれも有意差はなかった $(\mathrm{P}>0.1)$ ，ただし，HexaPOD (補正あり)は, 回転方向においては ExacTrac Robotics と同程度であったが, 三次元での位置誤差の標準偏差 が $0.03 \mathrm{~mm}$ で ExacTrac Roboticsの $0.20 \mathrm{~mm}$ に比べ小 さかった。

\section{4. 考 察}

本研究では, ExacTrac X-ray システムを HexaPOD と 組み合わせて使用する場合の位置補正法の考案と, そ の位置補正精度を検証した。補正なしでは, 三次元で の最大位置誤差が $4.52 \mathrm{~mm}$, 回転方向では 1.35 度の臨 床上問題となる移動座標の誤差を生じた。 しかし, 補正 することによって $1 \mathrm{~mm}$ 以内の位置精度に改善された。

HexaPOD の位置補正精度について, 武村ら ${ }^{6}$ は 3 軸 方向で $0.1 \mathrm{~mm}$ と高い精度を報告している. ただし，こ の報告では回転軸方向で評価されていない，本研究で

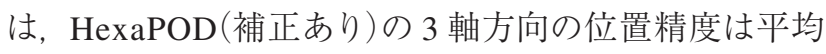
で $0.10 \mathrm{~mm}$, 回転軸方向では 0.14 度程度で, これまで
の報告6) と同様な精度であった，一方，補正なしでは 3 軸方向で最大 $4.50 \mathrm{~mm}$ の誤差が生じ, 正しい位置にカ ウチが移動していないため, ExacTrac X-ray システムと HexaPOD の組み合わせで使用できない. しかし，補正 を行うことによって ExacTrac Robotics と同程度の精度 で使用可能である.

ExacTrac Robotics の位置補正精度に関しては, 3 軸 方向は $0.3 \mathrm{~mm}$, 回転角度では $0.2 \sim 0.3$ 度以内で補正可 能と報告されている7,8). 本研究における検証では, 3 軸方向は平均で約 $0.14 \mathrm{~mm}$, 回転角度は 0.15 度程度で ほぼ同じもしくは，若干よい精度となった。

両カウチとも, 回転軸方向に故意に大きな誤差 $(3$ 度 程度)を発生させたとき, HexaPOD(補正あり)で 0.45 度, ExacTrac Robotics で 0.57 度の位置誤差が生じた。 Webster $ら^{9)}$ の報告では回転に関する記載はないが，3 軸の位置補正距離が大きい程, 位置の補正精度が低下 することが報告されており，可能な限り位置の移動補正 を小さくするセットアップが必要である.

Fig. 4 と Fig. 5 に示す HexaPOD(補正あり)と ExacTrac Robotics の位置補正精度の相違による線量分布へ の影響は，これまでの報告 ${ }^{1)}$ から臨床上問題にならない 誤差と考えられる. HexaPOD(補正あり)は, ExacTrac Robotics と比較してよりバラツキの少ない結果となっ た。これは, HexaPODの位置の移動精度が高いことを 
示している. ExacTrac Roboticsは roll と pitchのみが ExacTrac X-ray システムで制御され, 残りの 3 軸と yaw はリニアック装置のカウチで制御されるため, その幾何 学的位置精度に依存する, 一方, HexaPOD では, 複数 の関節をもつパラレル構造 ${ }^{10)}$ を有し, HexaPOD 本体が 6 軸同時移動を行うことで, 高精度な位置移動を可能に している.

本研究では, ExacTrac X-ray システムと HexaPOD を 組み合わせた使用を可能にするため, 簡易的な補正法 を考案した. しかし, HexaPOD は運動を逆次元的に求 める逆運動学 ${ }^{10)}$ で制御されているため, ExacTrac X-ray システムと組み合わせた場合に正確な位置座標の補正 計算を行うことは不可能である. ExacTrac X-ray システ 厶から HexaPOD 用の補正座標が直接的に計算可能で あれば, HexaPOD のパラレル構造の利点を生かした, さらに精度の高い位置補正が可能であると考えられる。

\section{5. 結 論}

本研究では, ExacTrac X-ray システムと HexaPOD シ ステムを組み合わせて使用する場合の補正法の考案と その精度を検証した，移動方式が異なる 6 軸カウチを 使用する場合は，位置座標の補正が必要となる，本研 究では, iBeam evo couch top を ExacTrac Robotics と同 様の 2 段階移動の操作を行うことによって, $1 \mathrm{~mm}$ 以内 の位置精度で補正可能となった，有意差検定でも BrainLAB 社製カウチを用いた場合と有意差はなかった (paired t-test，P>0.1)。しかし，回転軸方向の補正が大 きくなると誤差が大きくなる傾向にあった，正確な IGRT のためには，回転軸方向の誤差が最小となるよう なセットアップが推奨される.

本研究を進めるにあたり，貴重な情報を提供いただ いた，エレクタ株式会社メディカルフィジックス部，依 田＼cjkstart潔氏に深謝いたします。

\section{参考文献}

1) Hong TS, Tomé WA, Chappell RJ, et al. The impact of daily setup variations on head-and-neck intensity-modulated radiation therapy. Int J Radiat Oncol Biol Phys 2005; 61(3): 779-788.

2) Li XA, Qi XS, Pitterle M, et al. Interfractional variations in patient setup and anatomic change assessed by daily computed tomography. Int J Radiat Oncol Biol Phys 2007; 68(2): 581-591.

3) Takakura T, Mizowaki T, Nakata M, et al. The geometric accuracy of frameless stereotactic radiosurgery using a $6 \mathrm{D}$ robotic couch system. Phys Med Biol 2010; 55(1): 1-10.

4) Hawkins MA, Aitken A, Hansen VN, et al. Set-up errors in radiotherapy for oesophageal cancers--is electronic portal imaging or conebeam more accurate? Radiother Oncol 2011; 98(2): 249-254.

5) Lamba M, Breneman JC, Warnick RE. Evaluation of image- guided positioning for frameless intracranial radiosurgery. Int J Radiat Oncol Biol Phys 2009; 74(3): 913-919.

6）武村哲浩, 上田伸一, 能登公也, 他. 高解像度ディジタル カメラを用いた高精度放射線治療用 6 軸寝台の位置精度測 定法の検討。日放技学誌 2011; 67(9): 1174-1182.

7) Verbakel WF, Lagerwaard FJ, Verduin AJ, et al. The accuracy of frameless stereotactic intracranial radiosurgery. Radiother Oncol 2010; 97(3): 390-394.

8) Jin JY, Ryu S, Faber K, et al. 2D/3D image fusion for accurate target localization and evaluation of a mask based stereotactic system in fractionated stereotactic radiotherapy of cranial lesions. Med Phys 2006; 33(12): 4557-4566.

9) Webster GJ, Rowbottom CG, Mackay RI. Accuracy and precision of an IGRT solution. Med Dosim 2009; 34(2): 99-106.

10) 内山 勝. パラレルマニピュレータの機構と特性. 日本ロ ボット学会誌 1992; 10(6): 715-720. 


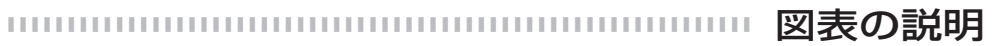

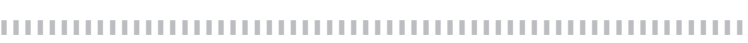

Fig. 1 HexaPOD での 6 軸補正の運用図

Fig. 2 使用した座標系

Fig. 3 ファントムのセットアップ

(a) ExacTrac X-ray システム用のリファレンススターと Clinac iX

(b) ExacTrac X-ray システム用のリファレンススターと HexaPOD 用のリファレンスフレームを装備した Synergy

Fig. 4 HexaPOD の補正精度
(a) 補正なし， 3 軸平行移動方向
(b) 補正なし, 3 軸回転方向
(c) 補正あり, 3 軸平行移動方向
(d) 補正あり，3 軸回転方向

Fig. 5 ExacTrac Robotics の補正精度
(a) 3 軸平行移動方向
(b) 3 軸回転方向

Table 1 HexaPOD の補正精度(平均, 標準偏差)
(a) 補正なし
(b) 補正あり

Ave: 絶対值の平均值, SD: 標準偏差, Max: 絶対值の最大誤差

Table 2 ExacTrac Robotics $の$ 補正精度(平均, 標準偏差)

Ave: 絶対值の平均值, SD: 標準偏差, Max: 絶対值の最大誤差 